\title{
Variantes e Invariantes de las memorias colectivas y emblemáticas en el contexto latinoamericano: el caso chileno
}

\author{
Variants and Invariants of collective emblematic memories in the \\ Latin American context: the chilean case.
}

\begin{abstract}
Adela Bork Vega*
Pontificia Universidad Católica de Valparaíso (PUCV), Valparaíso, Chile Universidad de Valparaíso (UV), Valparaíso, Chile

\section{Resumen}

Este artículo trata acerca de las memorias sociales y emblemáticas como entidades estructurales y de procesos, obtenidas a propósito de la violación de los derechos humanos en la región latinoamericana, en general, y de Chile, en particular. Las memorias emblemáticas son procesos sociales vinculados a contextos de reflexividad orientados a identificar la historicidad de los colectivos humanos. Los países de la región, producto de las dictaduras militares en la décadas del 60 y 70, sufrieron el de reconstrucción de las
\end{abstract}


memorias sociales ha logrado aportar a los procesos de justicia y de re-significación de esta parte de la historia en el pasado reciente.

Palabras clave: Memorias sociales. Derechos humanos. Chile. Procesos de justicia.

\section{Abstract}

This article refers to the social and emblematic memories as structural and processing entities obtained from the violation of human rights in Latin America and, particularly, in Chile. Emblematic memories are social processes related to reflectivity contexts focused on the identification of the historicity of human communities. Due to military dictatorships during the $60 \mathrm{~s}$ and 70s, regional countries suffered the impact of those regimes. However, the reconstruction of social memories has provided valuable elements to justice and re-signification processes of this part of the recent history.

Keywords: Social memories. Human rights. Chile. Justice processes.

“La memoria es un bien común, un deber y una necesidad jurídica y política"

(Recordatorio 40 años dictadura militar en Chile, septiembre 2013)

"Una sociedad sin memoria es similar a un sujeto que no posee fotos de su vida junto a los próximos y lejanos... imaginemos por un momento no tener ningún registro fotográfico"

(Recordatorio 30 años dictadura militar en Chile, septiembre 2003) 


\section{Introducción}

Con estas palabras que recuerdan los 40 y 30 años de la conmemoración de la dictadura militar en Chile, quisiera compartir con ustedes la presentación que he preparado para este congreso, producto de una investigación realizada en los últimos años.

Para efectos de esta comunicación, se presentarán tres ámbitos desde donde se organiza esta reflexión. El primero de estos ámbitos, da cuenta de algunas cuestiones de orden teórico en los cuales se sustenta la dimensión disciplinaria de las memorias sociales, soporte desde el cual se desarrolló el trabajo investigativo con resultados mediatos e inmediatos. Un segundo ámbito, remite a ciertas reflexiones obtenidas en la acción investigativa que facilitaron el desarrollo de la cátedra vinculada a los procesos de memoria, para estudiantes universitarios chilenos y extranjeros. Finalmente, se hacen explícitos ciertos debates y controversias en torno a las consecuencias que adquieren las memorias en contextos de modernizaciones aceleradas y/o en procesos de globalización intensiva (GARRETÓN, 2010).

El lugar desde donde elaboro estas ideas es la sociología, lo que implica que tiene los elementos que ésta disciplina ha desarrollado en este ámbito, pero al mismo tiempo, contiene las limitaciones propias de toda disciplina científica.

La memoria, como objeto de investigación e interés en nuestra región latinoamericana, - lamentablemente por los hechos acontecidos - , ha tenido un rendimiento teórico-disciplinario notable en los últimos años, generando una adhesión en equipos universitarios interdisciplinarios, en organizaciones e instituciones gubernamentales y no gubernamentales ligadas a las temáticas de Derechos Humanos (Instituto de Derechos Humanos, Colectivos referidos a Presos y Ejecutados Políticos, Agrupación de Detenidos Desaparecidos, entre otras). Esta situación, implica una modalidad de apreciar en este objeto de estudio, es decir, la memoria, aquellas formas explicativas-comprensivas vinculadas a los hechos y eventos sucedidos en esta región del mundo, en el pasado reciente. 
En este contexto, el pasado reciente se define desde la definición del tiempo en un sentido profundo, cuya característica principal es aquella temporalidad que articula de manera compleja el pasado, el presente y el futuro, superando la clásica definición del tiempo lineal que nos entrega la dimensión cronológica (RICOEUR, 1996; GIANNINI, 1987).

Nuestro pasado común en la región latinoamericana, finaliza el siglo pasado con varias décadas marcadas por la violencia política a partir del Estado, evidenciando como denominador común la violación sistemática de los derechos humanos y las posteriores modalidades con las cuales cada sociedad inicia ciclos de desprendimiento y elaboración de estas realidades traumáticas, definidas como transiciones políticas.

Las dictaduras militares o gobiernos de facto, como suelen caracterizarse a este tipo de sistemas autoritarios, permiten identificar un período histórico que hasta hoy, evidencia huellas de la fragilidad y precariedad en la construcción de las relaciones sociales. Lo anterior, influye directamente en los débitos de los sistemas políticos y en las transiciones democráticas exigidas por una superación de los límites delineados por la democracia formal, como organización de la vida en común (LACLAU, 2003).

\section{Algunas cuestiones referidas a las memorias en sus contenedores teórico-conceptuales}

Para algunos autores, lo primero a tener en cuenta es diferenciar la memoria en su dimensión cognitiva individual de aquella dimensión que remite a las orientaciones culturales con las cuales se constituye cada colectivo humano (GARCÉS; MILOS, 2007; STERN, 2000; GÜELL; LECHNER, 1999). En otras palabras, la distinción entre la dimensión psicológica clásica y aquella sustentada desde la disciplina sociológica en su dimensión histórica-cultural, es de vital importancia a la hora de trabajar sobre esta esfera, ya que permite configurar lo que se define como memoria colectiva. 
Bajo esta lógica, la lectura referida a la larga duración propuesta por Braudel (1968), puede convertirse en un soporte significativo a la hora de calibrar y ponderar a la memoria, como categoría en todas sus variantes/invariantes $y$, al mismo tiempo, en sus diversos matices.

Cuando se define la larga duración en términos teóricos, se remite a tres alcances fundamentales que tiene esta categoría: el primero de estos alcances, remite a los procesos que configuran las mentalidades y estructuras que pueden ser expresiones económicas, culturales, políticas, simbólicas, que se desarrollan a lo largo de la historia social de los colectivos humanos.

El segundo alcance, refiere a los procesos que se concatenan en eventos específicos y que se inscriben en algunas de las estructuras inscritas en las mentalidades anteriormente descritas. El último de los alcances referidos a la larga duración, expresa la circunstancia específica o la corta duración, aquello que se sitúa en una temporalidad que se encuentra en curso o está aconteciendo. Algunos autores definen a esto la contingencia y/o la coyuntura (BRAUDEL, 1968).

La larga duración en sus tres alcances y/o posibilidades, permite adentrarse con mayor espesura en el debate a propósito de las memorias. Se puede afirmar que apelar a las memorias y recurrir a éstas en una dimensión de larga duración, es considerar que en la emergencia de esta categoría, pueden advertirse al menos dos tipos de movimientos posibles: el movimiento de vinculación asimétrica y el movimiento de desestabilización.

a) El movimiento de vinculación asimétrica: conlleva a tener presente que los fenómenos asociados al trabajo de memoria, no pueden comprenderse de manera aislada, sino de modo relacional. Se hace necesario inscribir esta realidad en aquellas estructuras y mentalidades que se forjan y hacen visible un determinado colectivo social, sin embargo, ambas realidades no producen encajes simétricos por la dificultad que presenta la densidad histórica y la colonización del presente como coacción cultural (LECHNER, 2002; GIANNINI, 1987). 
Concretamente para el caso chileno, las mentalidades históricasculturales permiten adentrarse en la trama de relaciones que hacen de este país - en similitud a otros países de la región - una zona en la cual los fenómenos asociados a la colonización, a la persistencia/ resistencia de los pueblos originarios, a los procesos de mestizaje, a los sistemas tutelares, a la influencia de la religión católica, a la configuración de los sistemas jurídicos como reguladores del orden social; permiten configurar algunos ejes centrales en las formas como las relaciones sociales fueron construyendo estructuras materiales y simbólicas que hacen plausible los encuadres referenciales de aquello que es posible y permitido. Los estudios de De Gaulejac (1996), Garcés y Milos (1998), Jelin (2003), entre otros, dan cuento de esta condición. Para el caso chileno se pueden revisar los estudios de Goicovic (1988) y Montecino (1996).

Considerando estas estructuras y/o mentalidades analizadas en la obra de Gurvitch (1939), es posible comprender los eventos en términos de sus alcances y contenidos, ya que lo que acontece o está sucediendo, tiene un valor explicativo en la forma como busca apoyo y soporte en los encuadres referenciales, construidos por cada colectivo en su pasado reciente.

En otras palabras, se pueda afirmar que la dictadura chilena de la cual puedo referirme con mayores antecedentes, despliega un conjunto de acciones y procedimientos directos e indirectos, elabora lógicas y estrategias con fines de legitimación, estableciendo códigos tanto manifiestos como latentes, cuyo vínculo se encuentra directamente inscrito en las relaciones sociales construidas y "naturalizadas" a través de la trayectoria histórica del país. En esta perspectiva, la inscripción de la coyuntura y del estar sucediendo en los respectivos encuadres referenciales, genera espacios de ambigüedad y hace sinónimo legalidad con legitimidad, posibilitando arbitrios en cualquiera de las esferas de la vida social.

A estos encuadres referenciales, se agregan las coyunturas específicas que, para efectos de la dictadura militar en Chile y en Latinoamérica en general, es el período de la Guerra Fría y de los apoyos obtenidos desde el exterior. 
b) El movimiento de desestabilización: para considerar el trabajo de memoria, es necesario hacer consciente y evidenciar las disputas o luchas referidas a las "verdades históricas" y a las hegemonías de las "verdades oficiales".

Se actualiza la necesidad de revisar el rol de la historiografía clásica, por aquella forma de inflexión crítica que remite a connotar el trasfondo interpretativo que contiene la disciplina histórica. Por lo mismo, implica transitar hacia formas en las cuales el acto interpretativo no puede ser calificado de falta de objetividad, y el trabajo de archivos adquiere un sentido controversial, ya quien trabaja con archivos, acude con una lectura y posición necesaria de reconocerla de manera preliminar.

De manera complementaria, transitar desde la singularización a la pluralización de esta categoría, es, justamente, un espacio que supera la mera gramática. Hablar de memorias y no memoria, refiere a como los sujetos sociales, presionan por tener protagonismo en la interpretación histórica. La sólo constatación de los hechos y/o la descripción lineal de los eventos, se hace insuficiente cuando la complejidad de lo acontecido adquiere exigencias que superan los métodos tradicionales. En este dilema, para explicar y/o dar cuenta del pasado reciente, asoman aquellas perspectivas que permiten justamente evidenciar las disputas en curso, sea de manera manifiesta o latente, generando, por lo mismo, distintas posibilidades analíticas: elaborar descripciones densas, explicar interpretando y comprender significando (LIRA, 2011; SARLO, 2005; JELIN, 2003).

En una primera síntesis, las memorias y la larga duración propuesta por Braudel (1968), invitan a expresar de manera directa las luchas incesantes por visibilizar las realidades traumáticas y dolorosas que cada colectivo humano sobrelleva y, que por la vergüenza contenida y/o por los intereses que preservan, se tratan de ocultar, de atenuar y/o de negar (DE GAULEJAC, 1996).

Es dable destacar que para trabajar con memorias, es pertinente tener claridad que ésta categoría opera simultáneamente con otra categoría como es el olvido. Se puede afirmar, que estos pares conceptuales 
que constituyen antinomia en términos sociológicos, hace evidente la dialéctica implicada en la temporalidad como flujo incesante, al cual es difícil restarse individual y colectivamente (BERGSON, 2013).

Las memorias en su dimensión histórico - cultural, se articulan de manera contradictoria en la forma como los individuos sociales o colectivos con intereses específicos, luchan y presionan por visibilizar aquello que se quiere arrinconar y/o mostrar de manera deformada. Al mismo tiempo que se recupera aquello omitido o latente, los procesos de elaboración de las memorias van gestando ese olvido necesario para no transformarlo en inmovilismo social. En este proceso, los soportes materiales y simbólicos, que permiten hacer expresiva una historia determinada, posibilitan, al mismo tiempo, lo no traumático. En esta lógica, el recuerdo emerge y se construye como gesto relacional de consideración y valoración hacia los otros (HONNETH, 2010).

En los estudios de Güell y Lechner (2002), la memoria y el olvido son movimientos que evidencian la historicidad de las sociedades y el trabajo reflexivo que pueden llevar a cabo los individuos en su condición de actores y/o como sujetos sociales.

Si bien cada experiencia es vivida y significada de manera subjetiva, es relevante no encapsularla bajo esta nomenclatura, cuestiones que por las características contenidas en esta dimensión, expresan la radicalidad de la vida social en un momento determinado. Es evidente que el relato de lo traumático se expresa en esta dimensión singular, pero lo significativo es como la narrativa biográfica está plegada y envuelta en distintos registros que conecta lo subjetivo a la historia social, en todo lo que ella aporta sincrónica y diacrónicamente. Estas historias particulares se encuentran vinculadas irremediablemente entre el registro biográfico y la historia social. En esta línea reflexiva, los trabajos de Hobsbawm, nos posibilitan una mayor apertura y debate crítico, en especial los artículos contenidos en el texto "Gente poco Corriente" (2013).

Es dable recordar que uno de los teóricos más influyentes en esta temática es Maurice Halbwachs $(1968,1994)$, quien haciendo mención a la constitución de las memorias colectivas, las ordena en base al recuerdo y olvido en términos categoriales. Cada época, trasuntando lugares, 
fechas y acontecimientos que transitan entre ese recuerdo próximo y el olvido que permite la urdimbre social.

Las memorias colectivas con sus respectivos procesos de olvidos, actúan como caja de resonancia de las sociedades y, es justamente ese ruido que en momentos confunde y no permite captar las voces y narrativas de aquellos que disputan un espacio social para el reconocimiento y ratificación social (HONNETH, 2010).

La forma de consolidación de las memorias colectivas para procesos traumáticos, se despliega en lo que la literatura reconoce como memorias emblemáticas. Lo emblemático se liga a una constatación directa como en la re-producción de lo social referido a hechos traumáticos. Hay memorias que se dispersan, hay resistencia y/o existe negación para incorporarlas en la lógica global. Esta dispersión y/o negación pudiera explicarse, sea por los juegos de poder reflejados en la hegemonía de la interpretación histórica, sea por la velocidad con la cual se enfrentan los procesos de cambio social, o simplemente por los grados de levedad que caracterizan a ciertos momentos históricos, los cuales pueden ser explicados desde diversos ámbitos disciplinarios.

Stern (1998), estudioso de las memorias emblemáticas, caracteriza a través de algunos criterios, lo que a su juicio son elementos centrales en la configuración de estas memorias:

1) La historicidad: las memorias emblemáticas precisan capturar aquellas rupturas, quiebres, y/o fisuras que enfrentan las sociedades en sus procesos de re-producción social;

2) La autenticidad: la existencia de hechos/eventos concretos que independiente a la interpretación, no pueden ser negados o sustraídos de la dis-continuidad histórica (cronología de los hechos);

3) La amplitud: la identificación de varios recuerdos - aunque éstos pudieran ser contradictorios y/o fragmentarios - precisan formas recuperación e integración;

4) La proyección en espacios públicos: la expresa decisión de sacar del espacio privado aquellos recuerdos traumáticos y elementos de las memorias colectivas, generando la circulación de éstos en 
diversos sectores sociales y/o actores, validando lo público como espacio material y simbólico.

5) Los portavoces: son los líderes que proyectan en tiempos diferidos estas memorias colectivas, organizándolas y proyectándolas en los diversos espacios que ofrece la sociedad; ésta última, reconoce en los portavoces una consecuencia en sus comportamientos.

\section{Alcances y resultados asociados a la cátedra de memoria}

El trabajo de indagación científica y la posterior consolidación en la cátedra ofrecida a los jóvenes universitarios chilenos y extranjeros, se orientó teórica y epistémicamente a partir de las memorias emblemáticas, facilitando la comprensión de los procesos de recuperación de las memorias sucedidos en el Chile post-dictadura.

En este análisis se pueden encontrar algunos datos que ratifican la vasta producción en este ámbito de las ciencias sociales.

De manera principal, la fractura producida por la dictadura militar fue erosionando las relaciones sociales, provocando temor y miedo de manera secuencial y bajo modalidades distintas, de acuerdo a cada etapa de este sistema impuesto. No obstante, en la misma experiencia traumática se fue acopiando los elementos que posteriormente se organizaron de un modo que fue posible re-configurar y re-significar los recuerdos como portadores de memorias colectivas, re-situadas bajo la perspectiva de lo emblemático.

Los diversos actores aluden a formas sociales en las cuales los criterios de Stern, resultan clarificadores y altamente complejos, sea por la explicación de los mismos, como por los alcances insinuados en los contextos de lo cotidiano y de la producción de lo político como espacio de coexistencia social.

Los datos contenidos en los informes de investigación, permiten evidenciar el posicionamiento categórico de los portavoces como actores claves en la sociabilidad y difusión de las memorias emblemáticas a un sector amplio de la sociedad. Las diversas organizaciones vinculadas a la defensa de los Derechos Humanos (DD.HH), fueran 
mostrando de manera directa y radical, como una realidad que se pretendió encapsular, se difumina en variadas direcciones, haciendo imposible el ocultamiento y/o la negación.

En Chile, si bien el reconocimiento fue paulatino y discreto en la década del noventa, en la actualidad es un fenómeno que ha logrado una amplitud significativa, impregnando diversos espacios, actores e instituciones. Al cumplir 40 años del golpe militar, cuestión sucedida en el mes de septiembre del año 2013, se constata como algunos individuos y organizaciones que auspiciaron y promovieron esta fractura política (líderes de los partidos de derecha, algunos, sectores empresariales, Fuerzas Armadas), fueron reconociendo su participación directa e indirecta, incorporando la autocrítica y la vergüenza de haber amparado el sistema, con sistemas de justificación de carácter inexcusables, tanto en el pasado reciente, como en la actualidad.

A lo anterior, se suma la visibilidad que tienen las memorias emblemáticas del pasado reciente en la sociedad chilena, haciendo del espacio público un lugar privilegiado para comunicar y motivar sobre la excepcionalidad de un período marcado por la arbitrariedad y falta de humanidad. Las nuevas generaciones aprenden una parte de la historia silenciada, justamente, a partir de lo que pasa y se expresa en esos espacios públicos.

Las intervenciones en el espacio público van desde las manifestaciones, los recordatorios y las instalaciones que, desde las artes y la estética, van generando los soportes necesarios para que aquel transeúnte que va de manera desprevenida sea sorprendido por aquello que rompe lo monocorde de esa rutina.

El golpe militar chileno, se encuentra definido desde los hechos y desde una lógica global, como un acto de barbarie y atentatorio a los procesos civilizatorios en los cuales las sociedades reflexivas constituyen lo social (MORIN, 2007). En este ámbito, se puede afirmar que respecto al criterio de autenticidad de las memorias emblemáticas, éste se cumple a cabalidad cuando la violación a los derechos humanos durante la dictadura militar no pueden ser negados, considerando cuestiones centrales como: la emergencia de testimonios de manera sistemática en distintos lugares del país; litigios pendientes en los Tribunales de 
Justicia, en las Cortes de Apelaciones y en la Corte Suprema; se identifican lugares y espacios físicos en los cuales se llevaron a cabo los diversos sistemas de tortura, lo que implica las diversas violencias: físicas, psicológicas, sexuales, patrimoniales, entre otras; se graban e inscriben aquellas huellas simbólicas de los hechos acontecidos en diversos registros que van siendo acumulados y expuestos.

Cualquier explicación, ya no logra poner en duda el hecho mismo de las violaciones de los Derechos Humanos. Los sistemas de justificación aún presentes se buscan en los intersticios de las relaciones sociales de poder y de control social: "fue para recuperar el orden social, era para evitar el caos, se detuvo el camino de la politización de la sociedad". Lamentablemente, similares sistemas de justificación, se instalaron en la sociedad brasileña. Lo mismo aconteció en la sociedad uruguaya o argentina.

Complementando la idea anterior, en el ejercicio de la memoria los recuerdos no son meras expresiones subjetivas, son las historias mínimas hilvanadas en la trama de la historia social (HOBSBAWM, 2013).

En síntesis, nos situamos en donde los diversos actores han logrado articular junto a los recuerdos y a la evocación, los hechos en su persistencia de memoria, en su elaboración como expresión de colectivos, re-significando la historicidad como acción reflexiva y, no sólo como mandato cultural desde la exterioridad.

\section{Debates y dilemas con alcances diferenciados}

Considerando las posibilidades que entregan este objeto de estudio - como son las memorias emblemáticas - que son a la vez asibles e inasibles, es relevante generar puntos de inflexión bajo modalidades de-centradas y críticas en términos disciplinarios y en su componente de acción política.

Se pueden advertir al menos dos nudos críticos que se consideran centrales en el actual contexto de producción teórica referida a la temática. En este sentido, se aprecian debates y controversias a propósito de las memorias y los efectos en los actuales contextos en los cuales 
transitan las sociedades en sus procesos de cambios y transiciones, a nivel micro y macro social.

\section{a) La divulgación de la temática}

El trabajo sobre y acerca de las memorias ha logrado permear y afectar a los distintos grupos y clases sociales, que por sus opciones ideológicas, de manera contumaz fueron indiferentes a la ruptura y violencia política sucedidas en el pasado reciente de la sociedad chilena. Bajo esta condición, el trabajo sistemático de algunos portavoces ocupando distintos escenarios nacionales e internacionales, fue permitiendo que los hechos fueran paulatinamente aceptados de manera individual y colectiva, provocando distancias y críticas a sistemas basados en la barbarie humana.

Al mismo tiempo, la expresión de no mirar al pasado, no hablar de lo acontecido y la tendencia a estar siempre orientado al presente, fue igualmente revertido, en parte, a través de las prácticas llevadas a cabo desde el trabajo de reconstrucción de memorias. Este comportamiento, evidentemente ha sido valorado y no hubiera sido posible sin las actuaciones de quienes movilizaron recursos, energías, investigaciones y acciones para evitar el olvido y hacer de la memoria un gesto de re-significancia metódica y de posicionamiento ético-político. En este ámbito, las agrupaciones y organizaciones políticas de defensa de los derechos humanos y de promoción de la memoria como patrimonio tangible e intangible, son por definición las instituciones que procuran sostener este quehacer $y$, que se encuentran activas frente a cualquier intento de socavar el trabajo logrado a través del tiempo (Agrupación de Familiares de Detenidos Desaparecidos, Familiares de Ejecutados Políticos, Museo de la Memoria, por mencionar alguna de estas entidades).

No obstante, uno de los debates en torno a esta temática se sitúa a propósito de cómo la sociedad actual, afectada por múltiples cambios tecnológicos; de flujos constantes en términos de tangibles e intangibles; de modernizaciones vertiginosas; de demandas referidas a 
las identidades individuales y colectivas, ha podido instalar a las memorias como un objeto integrado a la vasta producción de artefactos culturales.

Concretamente y siguiendo las reflexiones críticas de varios autores (Güell, Lechner y Sarlo), podemos interrogar sobre el peso que puede tener la industria cultural en fenómenos sensibles y distintos como éste. En estas críticas, se expresan de manera directa algunas tensiones y dilemas cuando refieren a los lugares de memoria y, a las modalidades de aproximación en los actuales contextos enunciados precedentemente. La identificación de los lugares de memoria hace posible que sean integrados como parte de los circuitos turísticos y cartografiados en el material producido por este tipo de actividad comercial. Esta acción, en momentos ha generado un vaciamiento del contenido que lo inspira, ha generado una des-materialización de los significados, posibilitando una deformación del sentido. En síntesis, potencialmente pueden gestarse formas de banalización.

Podemos visualizar que este dilema enfrenta a dos grupos con premisas que, siendo próximas, marcan diferencias. De una parte, hay quienes afirman que es mejor una amplia difusión de los lugares de memoria, con el fin de que un mayor número de personas conozca materialmente lo sucedido en el pasado reciente. De otra parte, hay quienes sostienen que las memorias son patrimonios tangibles e intangibles, las cuales no pueden prestarse a un juego de mercantilización en los actuales escenarios políticos, económicos e ideológicos del país.

Las memorias son patrimonios a preservar, lo que implica que el dilema se sostenga en el tiempo y que asomen nuevamente en las coyunturas las mentalidades y estructuras en las cuales se inscriben las prácticas culturales de los sujetos.

\section{b) Perspectiva interdisciplinaria}

Uno de los gestos de la memoria es superar la hegemonía de disciplinas clásicas referidas a las memorias (sociología, historia, 
psicología). Este objeto/sujeto de interés y de intervención, es de carácter complejo en el cual se precisan enfoques diversos para el conocimiento y profundización de la temática, motivando al quehacer mancomunado de las ciencias, con el fin de hacer vinculante la producción científica con las acciones políticas necesarias en un determinado tiempo social.

En términos interdisciplinarios, el trabajo de reconstrucción de memorias posibilita un despliegue significativo del quehacer metodológico, integrando distintos dispositivos y niveles, lo que facilita aprehender los matices y aristas de quienes se encuentran volcados hacia la recuperación del pasado reciente. Los enfoques biográficos adquieren su mayor expansión cuando se disponen como soporte metodológico en este ámbito, haciendo plausible formas creativas para el tratamiento de realidades que, siendo dolorosas en el acto mismo de recordar, van gestando incipientemente las formas de reparación individual y colectiva (LIRA, 1999).

\section{c) La dimensión política de las memorias}

El trabajo en torno a las memorias colectivas y emblemáticas, en su componente principal, conlleva una acción política al reflexionar en un movimiento de larga duración a propósito de la historicidad de las sociedades en las cuales acontece la vida social. Por antonomasia, las memorias y el trabajo de recuperación de aquellas, implica una forma de implicación que remite a cuestionar el tipo de organización social llevada a cabo; revisa las concepciones sobre el orden construido y, potencialmente el que puede seguir preservándose; identifica a los individuos como sujetos y/o actores sociales; pone al descubierto las relaciones sociales en su componente material y simbólico, por citar algunos de los elementos puestos en tensión.

El trabajo en torno a las memorias, trasunta la acción política como una forma de acción afirmativa en el sentido de imaginar y reflexionar respecto al destino de las sociedades, de considerar y tomar el peso de la 
vida en común, es decir, pone en jaque los sistemas hegemónicos que se re-producen facilitando la exclusión y desconsideración social.

Las sociedades que trabajan a partir de la recuperación de las memorias, pueden enfrentar de mejor forma los debates y dilemas de la vida en común a través de la diferencia. De manera complementaria, discutir re-significando el pasado reciente, posibilita no desprenderse de los hechos como un gesto de olvido, sino que evocar para poder volver sobre aquello y generar formas reflexivas de que es lo permitido y posible para la vida social. No hay exceso en el reconstruir las memorias sociales y emblemáticas, más bien el acto de realizarlas se constituye en los legados culturales que precisan las sociedades que aquilatan la historicidad como actos reflexivos.

El nunca más de las sociedades dañadas por eventos traumáticos, no pueden ser exclusivamente a través de decretos jurídicos, sino que al mismo tiempo de valorar este tipo de soporte, es saber elaborar y usar estos dispositivos desde y sobre las memorias, pensando que son la trama social manifiesta y latente. En síntesis, son los cimientos de una sociedad que se piensa, imagina y se proyecta.

Siguiendo a Arendt, las sociedades precisan de memoria en su componente de evocación, de elaboración y de problematización. Podemos afirmar, que entre gesto, cuerpo y palabra, lo que se articula son los vínculos que nos permiten construir los lazos sociales, cuestión central en las sociedades históricas que se permiten, a partir de la crítica del presente, revisar el pasado, con el fin de disponerse a imaginar la construcción del futuro.

“Hacer memoria es recordar y, si nos ajustamos a lo etimológico de la palabra, recordar, es pasar por el corazón".

\section{Referencias}

ARENDT, H. La condición humana. Barcelona. Paidós, 2005.

BALANDIER, G. Gurvicth. Paris: Ediciones PUF, 1972. 
BERGSON, H. El pensamiento y lo moviente. Buenos Aires: Editorial Cactus, 2013.

BRAUDEL, F. La historia y las ciencias sociales. Madrid: Alianza Editorial, 1968. DE GAULEJAC, V. Les sources de la honte. Paris: Éditions Desclée de Brouwer, 1996.

GARCÉS, M.; MILOS, P. Memorias para un nuevo siglo. Chile, miradas a la segunda mitad del siglo XX. Santiago: LOM Ediciones, 1998.

GARRETÓN, M.; GARRETÓN, R. La democracia incompleta en Chile: La realidad tras los rankings internacionales. Revista de Ciencia Política, v. 30, n. 1, 2010.

GIANNINI, H. La "Reflexión" Cotidiana. Hacia una Arqueología de la Experiencia. Santiago de Chile. Editorial Universitaria, 1987.

GOICOVIC, I. Sujetos, mentalidades y movimientos sociales en Chile. Santiago: CEME, 1998.

GURVITCH, G. Essais de sociologie. Paris. Librairie du Recueil Sirey, 1939.

GURVITCH, G. Revue francaise de sociologie, v. 7, n. 1, ene.-mar. 1966.

HALBWACHS, M. La mémoire collective. Paris: Ediciones PUF, 1968.

HALBWACHS, M. Les cadres sociaux de la mémoire. Paris: Ediciones Albin Michel, 1994.

HOBSBAWM, E. Gente poco corriente. Barcelona: Editorial Crítica, 2013.

HONNETH, A. Reconocimiento y menosprecio. Buenos Aires: Katz Editores, 2010.

JELIN, E. Los derechos humanos y la memoria de la violencia política y la represión: la construcción de un campo nuevo en las ciencias sociales. Cuadernos del IDES, n. 2, oct. 2003.

JELIN, E. Monumentos, memoriales y marcas territoriales. Madrid: Siglo XXI, 2003.

LACLAU, E. Contingencia, hegemonía, universalidad. Buenos Aires: Fondo de Cultura Económica, 2003. 
VEGA, A. B.

LECHNER, N.; GÜELL, P. Las sombras del mañana. Santiago: LOM Ediciones, 2002.

LIRA, E. Las suaves cenizas del olvido. Vía chilena de reconciliación política 18141932. Santiago: LOM Historia-DIBAM, 1999.

MONTECINO, S. Madres y huachos. Santiago: Editorial Sudamericana, 1996.

MORIN, E. Breve historia de la barbarie en occidente. Buenos Aires: Paidós, 2007.

RICOEUR, P. Du texte à l'action. Essais d'herméneutique II.Paris. Éditions du Seuil, 1986.

SARLO, B. Tiempo presente. Buenos Aires: Siglo XXI, 2001.

SARLO, B. La pasión y la excepción. Buenos Aires: Siglo XXI, 2003.

SARLO, B. Tiempo pasado. Cultura de la memoria y giro subjetivo. Buenos Aires: Siglo XXI, 2005.

SARLO, B. La máquina cultural. Buenos Aires: Emecé Editores S.A.: Seix Barral, 2007.

STERN, S. De la memoria suelta a la memoria emblemática: hacia el recordar y olvidar como proceso histórico. Chile, 1973-1998. In GARCÉS, M.; MILOS, P. Memorias para un nuevo siglo. Chile, miradas a la segunda mitad del siglo XX. Santiago: LOM Ediciones, 1998.

Recebido: 12/12/2015

Received: 12/12/2015

Aprovado: 03/02/2016

Approved: 02/03/2016 